\title{
CONTRIBUIÇÃO AO ESTUDO DO SISTEMA EXCRETOR DO PÂNCREAS EM MUARES (EQUUS CABALLUS X EQUUS ASINUS) $\S$
}

\author{
Irvênia Luiza de Santis PRADA * \\ Antonio FERNANDES FILHO * \\ Vicente BORELLI **
}

RFMV-A/26

Prada, I. L. de S. et al. - Contribuição ao estudo do sistema excreto do pâncreas em muares (Equus caballus $x$ Equus asinus). Rev. Fac. Med. vet. Zootec. Univ. S. Paulo, 11:271-93, 1974 .

RESUMo: O sistema excretor do pâncreas de 30 muares adultos (15 machos e 15 fêmeas), examinado mediante dissecção, mostrou, como vias mais importantes, o ducto principal (de Wirsung), o ducto acessório (de Santorini), o ducto do lobo direito e o ducto do lobo esquerdo, além de outros numerosos coletores que a clas vão ter. O ducto do lobo esquerdo estende-se, sempre, apenas ao longo do território que the corresponde, enquanto o ducto do lobo dirito percorre, em 13,3\% dos casos, também a porção caudal do lobo esquerdo.

Quanto ao ducto acessório (de Santorini), alcança a parede duodenal em $80,0 \%$ das peças e prende-se, por sua extremidade central, no ducto principal (de Wirsung) - (56,7\%), no ducto do lobo esquerdo (20,0\%), no ducto do lobo direito $(6,7 \%)$ ou em afluente conspicuo do primeiro ducto $(6,7 \%)$, do terceiro $(6,7 \%)$ e do segundo $(3,3 \%)$.

Surpreendemos, ainda, a presenca de via anastomótica a interligar, algumas vezes $(13,3 \%)$, os ductos dos lobos direito e esquerdo.

UnITERmos: Muares *; Pâncreas *; Vias excretoras*; Anatomia*; Aparelho digestivo *.

\section{INTRODUÇAO E LITERATURA}

Com a finalidade de apreciar comparativamente as vias excretoras do pâncreas em alguns dos eqüídeos, examinamos agora o comportamento dos principais coletores de drenagem da glândula dos muares, para somar resultados aos obtidos por PAIVA et al. ${ }^{15 * * *}$ e PEDUTI NETO ${ }^{16}$, em trabalhos alusivos, por ordem, a eqüinos e asininos. E ainda, damos continuidade à série de estudos similares, sobre o assunto, inicialmente dedicados a zebuínos, taurinos e búfalos, segundo as respectivas publicações de PRADA, et al.19 (1966), PRADA ${ }^{17}$ (1970) e PAIVA et al. ${ }^{14}$ (1972).

§ Trabalho apresentado à III Jornada Científica da Faculdade de Ciências Médicas e Biológicas de Botucatu, realizada de 11 a 15 de dezembro de 1973.

* Professor Assistente Doutor.

* Professor Livre Docente.

Departamento de Cirurgia e Obstetricia da Faculdade de Medicina Veterinária e Zootecnia da USP.

*** Trabalho comunicado ao IX Congresso Brasileiro de Anatomia, Florianópolis (SC), julho de 1972 . 
PRADA, I. L. de S. et al. - Contribuiçāo ao estudo do sistema excretor do pâncreas em muares (Equus caballus $\mathrm{x}$ Equus asinus). Rev. Fac. Med, vet. Zootec. Univ. S. Paulo, 11: $271-93,1974$.

Levamos também em conta que, entre eqüinos, asininos e muares, PRADA et al. 18 surpreenderam sugestivos aspectos discordantes, ao analisarem as comunicações do sistema excretor do órgāo com o duodeno, talvez ligadas a razões de ordem embriológica, explicadas por LORDY 11. (1940).

De outra parte, as informaçōes exaradas na maioria dos livros consultados, já suscintas, referem-se apenas a equiinos. Com esta investigação, poderemos caracterizar disposiçōes diferentes das ai descritas e peculiares ao pâncreas dos muares, ou simplesmente confirmar a validade da conduta de BOURDELLE \& BRESSOU ${ }^{1}$ (1937), que oferecem relato único e genérico para esta glândula dos equiuideos.

Nos livros de texto, encontramos sempre referência à presença de dois ductos excretores para o pâncreas dos eqüinos, embora designados diversamente, ou seja: ductus pancreaticus e ductus pancreaticus accessorius, conforme citação de ZANOLLI 23 (1910), BRADLEY 2 (1922), SCHMALTZ 20 (1928) e ELLENBERGER \& BAUM 5 (1932); ducto pancreático principal ou de Wirsung e ducto pancreático acessório ou de Santorini, segunđo escrevem BRUNI \& ZIMMERL 3 (1947); ducto principal ou de Wirsung e ducto acessório, secundário, ázigos ou de Santorini, à maneira de FAVILLI 6 (1931); ducto pancreático e ducto pancreático acessório, como assinalam SISSON \& GROSSMANN 22 (1965); ducto principal ou de Wirsung e ducto acessório, de acordo com GONZALEZ Y GARCIA \& ALVAREZ 7 (1961); ducto pancreático maior e ducto acessório, conforme registra ZIMMERL 24 (1949); ductus pancreaticus major ou de Wirsung e ductus pancreaticus minor, accessorius ou de Santorini, como encontramos em SCHUMMER \& NICKEL 21 (1960); ducto de Wirsung e ducto de Santorini, segundo referência de KATO ${ }^{8}$ (1961); canal principal ou de Wirsung e canal acessório ou de Santorini, de acordo com LESBRE 10 (1922) e CARADONNA 4 (1930); canal principal ou de Wirsung e canal acessório ou ázigos, conforme escrevem MONGIARDINO 12 (1903), MONTANE \& BOURDELLE 13 (1913) e LEPOUTRE 9 (1921); canal principal ou de Wirsung e canal acessório, ázigos ou de Santorini, como referem BOURDELLE \& BRESSOU ${ }^{1}$ (1937).

ZANOLLI 23 (1910), LESBRE 10 (1922) e GONZALEZ Y GARCIA \& ÁLVAREZ ${ }^{7}$ (1961) citam ainda que o ducto principal (de Wirsung) resulta da associação de raízes, ou seja, respectivamente duas, duas ou três e três. Já outros AA. fazem ainda menção ao comportamento do ducto acessório (de Santorini); assim, BRADLEY 2 (1922), LESBRE 10 (1922), CARADONNA 4 (1930), FAVILLI ${ }^{6}$ (1931), BOURDELLE \& BRESSOU ${ }^{1}$ (1937) e GONZALEZ Y GARCIA \& ÁLVAREZ 7 (1961) apontam-no a nascer do ducto principal (de Wirsung). Para ELLENBERGER \& BAUM 5 (1932), este fato é de ocorrência inconstante, enquanto BRUNI \& ZIMMERL 3 (1947) e SISSON \& GROSSMANN 22 (1965) marcam também a alternativa de estabelecer-se conexāo do ducto acessório (de Santorini) com a raiz esquerda do ducto principal (de Wirsung).

Relativamente ao trabalho de PAIVA 15 (1973), já referido, verificamos que, após dissecarem o sistema excretor do pâncreas de 30 eqüinos (15 machos e 15 fêmeas) adultos, sem raça definida, encontram o ducto principal (de Wirsung) a resultar sempre da convergência 
PRADA, I. I. de S. et al. - Contribuição ao estudo do sistema excretor do pâncreas em muares (Equus caballus $\mathrm{x}$ Equus asinus). Rev. Fac. Med. vet. Zootec. Univ. S. Paulo, 11: $271-93,1974$

de duas raizes, tais sejam, o ducto do lobo direito e o ducto do lobo esquerdo. A essas vias vêm ter inúmeros afluentes, isto é, por ordem: cinco $(20,0 \%)$, sete $(20,0 \%)$, dois $(13,3 \%)$, seis $(13,3 \%)$, um $(10,0 \%)$, três $(6,7 \%)$, quatro $(6,7 \%)$, oito $(3,3 \%)$, $\operatorname{dez}(3,3 \%)$ e treze $(3,3 \%) ; \operatorname{dez}(20,0 \%)$, sete $(13,3 \%)$, doze $(13,3 \%)$, oito $(10,0 \%)$, cinco $(6,7 \%)$, seis $(6,7 \%)$, nove $(6,7 \%)$, onze $(6,7 \%)$, catorze $(6,7 \%)$, três $(3,3 \%)$, quatro $(3,3 \%)$ e treze $(3,3 \%)$; dezesseis $(16,7 \%)$, catorze $(10,0 \%)$, quinze $(10,0 \%)$, dezessete $(10,0 \%)$, dezoito $(10,0 \%)$, nove $(6,7 \%)$, dez $(6,7 \%)$, vinte e cinco $(6,7 \%)$, onze $(3,3 \%)$, doze $(3,3 \%)$, treze $(3,3 \%)$, vinte $(3,3 \%)$, vinte e um $(3,3 \%)$, vinte e três $(3,3 \%)$ e vinte e seis $(3,3 \%)$; em respectivamente $13,3 \%, 90,0 \%$ e $80,0 \%$ dos órgãos, conforme citam esses A., alguns dos aludidos afluentes destacam-se pela amplitude de calibre e da correspondente região de escoamento. Elucidam ainda que o ducto do lobo direito escoa, em $6,7 \%$ das ocasiões, também a porção caudal do lobo esquerdo de onde acolhe nove $(3,3 \%)$ e doze tributários (3,3\%). Por sua vez, continuam, o ducto acessório (de Santorini), caracterizado em $96,7 \%$ das dissecçōes, exibe sua extremidade central, livre, raramente $(3,3 \%)$, ou a abrir-se diretamente: no ducto principal (de Wirsung) - $(76,6 \%)$, no ducto do lobo esquerdo $(10,0 \%)$, no ducto do lobo direito $(3,3 \%)$ e no limite entre o ducto principal (de Wirsung) e o ducto do lobo esquerdo $(3,3 \%)$; não recebe tributários algumas vezes $(26,7 \%)$ mas acolhe-os na maior parte dos casos $(70,0 \%)$, e em número variável, vale dizer: um $(26,7 \%)$, dois $(23,3 \%)$, três $(6,7 \%)$, quatro $(6,7 \%)$, seis $(3,3 \%)$ e oito $(3,3 \%)$. Por fim, os AA. acusam a presença de coletores anastomosados a interligarem os ductos dos lobos direito e esquerdo por intermédio de massa glandu- lar disposta caudal $(56,7 \%)$ ou cranialmente $(6,7 \%)$ ao anel portal, bem como diferentes secções do ducto do lobo direito $(3,3 \%)$.

Por sua vez PEDUTI NETO 16 (1972), ef tuando pesquisa similar, em 30 asininos da raça Pêga, adultos (15 machos e 15 fêmeas), conclui que o ducto principal (de Wirsung), constitui-se pela união do ducto do lobo direito e ducto do lobo esquerdo, vias às quais vem ter numerosos coletores, isto é, respectivamente: cinco $(23,3 \%)$, seis $(20,0 \%)$, sete $(20,0 \%)$, quatro $(16,7 \%)$, três $(10,0 \%)$, dois $(3,3 \%)$, oito $(3,3 \%)$ e dez $(3,3 \%)$; dezessete $(16,7 \%)$, treze $(13,3 \%)$, quinze $(13,3 \%)$, nove $(10,0 \%)$, catorze $(10,0 \%)$, dezoito $(10,0 \%)$, $\operatorname{dez}(6,7 \%)$, doze $(6,7 \%)$, dezesseis $(6,7 \%)$, sete $(3,3 \%)$ e dezenove $(3,3 \%)$; dezenove $(16,7 \%)$, vinte $(13,3 \%)$, vinte e um $(10,0 \%)$, vinte e três $(6,7 \%)$, vinte e quatro $(6,7 \%)$, vinte e cinco $(6,7 \%)$, trinta e um $(6,7 \%)$, catorze $(3,3 \%)$, vinte e dois $(3,3 \%)$, vinte e sete $(3,3 \%)$ e vinte e nove $(3,3 \%)$. Dentre os referidos coletores, alguns merecem a qualificação de conspicuos,ou seja, por ordem: um $(40,0 \%)$; dois $(43,3 \%)$, um $(40,0 \%)$, três $(10,0 \%)$ e quatro $(3,3 \%)$; um $(50,0 \%)$, dois $(20,0 \%)$ e três $(3,3 \%)$. Quanto ao ducto acessório (de Santorini), o A. encontra-o a comunicar-se, pela extremidade central, com o ducto principal (de Wirsung) - $(53,3 \%)$, com o ducto do lobo direito $(23,3 \%)$ e com o do esquerdo (23,3\%). Para o ducto acessório (de Santorini) convergem três $(36,7 \%)$, um $(20,0 \%)$, dois $(20,0 \%)$, cinco $(13,3 \%)$ e quatro $(\mathbf{1 0 , 0 \% )}$ afluentes. O A. assinala ainda anastomoses relacionando entre si diferentes vias, ou seja: os ductos dos lobos direito e esquerdo $(10,0 \%)$, o ducto principal (de Wirsung) e o do lobo esquerdo $(3,3 \%)$, o ducto principal (de Wirsung) e o ducto acessório (de Santorini) - $(3,3 \%)$. 
PRADA, I. L. de S. et al. - Contribuição ao estudo do sistema excretor do pâncreas em muares (Equus caballus $\mathrm{x}$ Equus asinus). Rev. Fac. Med. vet. Zootec. Univ. S. Paulo, 11: $271-93,1974$

\section{MATERIAL E METODO}

Coletamos 30 pâncreas * e segmento intestinal correspondente às papilas duodenais maior e menor, de 15 muares machos (m) e 15 fêmeas (f), adultos com diferentes e não conhecidas idades, procedentes de várias regiōes dos Estados de São Paulo, Minas Gerais e Mato Grosso, e abatidos no Matadouro "Primeat" em Braganca Paulista (SP).

Inicialmente, submetemos todas as peças à "prova de ar", ou seja, estando o duodeno aberto ao longo da grande curvatura e a mucosa lavada, injetávamos ar no sistema excretor da glândula, já submersa em água, mediante canalização do ducto principal (de Wirsung) e apreciávamos a eventual ocorrência de borbulhamento na superficie interna do aludido trato. Procedíamos, em seguida, à injeção dos órgãos, pela mesma via, com "neoprene latcx 650" corado para, depois de fixá-los em solução aquosa de formol a $10 \%$, dissecá-los pela face dorsal, esquematizá-los e fotografar alguns deles.

Como SCHUMMER \& NICKEL 21 (1960) descrevem para os eqüinos, consideramos. no pâncreas dos muares, além das faces dorsal e ventral, os lobos direito e esquerdo - a circundarem o anel portal - e o corpo, massa glandular dirigida ao duodeno. Atentamos também para a ponte, lâmina pancreática colocada caudalmente ao referido anel, que ajuda a definir.

\section{R E S U L T A D O S}

Conforme verificamos nas peças dissecadas, integram o sistema excretor do pâncreas dos muares (Figs. 1, 5, 6), como vias mais importantes, o ducto principal (de Wirsung) - (A), o ducto do lobo direito
(B), o ducto do lobo esquerdo (C) e o ducto acessório (de Santorini) - (D), além de outros numerosos coletores que a elas vāo ter, segundo diferentes combinaçōes (Figs. 2, 3, 4, 11); alguns destes, que designaremos, sempre, de conspícuos, destacam-se pela maior amplitude de calibre e da correspondente região de escoamento.

A - O ducto principal (de Wirsung), calibroso e de comprimento variável (Figs. $1,5,6,9)$ mostra-se, em todas as preparações, a nascer da convergência dos ductos dos lobos direito e esquerdo. Estende-se axialmente ao longo do corpo da glândula e dirige-se à papila duodenal maior recebendo, durante o trajeto, variável número de afluentes (Fig. 2). Sem considerar a eventual dependência do ducto acessório (de Santorini) ao ducto principal (de Wirsung), contamos três tributários - 7 vezes $(23,3 \% \pm 7,7-$ Obs. If, $3 \mathrm{f}, 6 \mathrm{f}, 15 \mathrm{~m}$, $16 \mathrm{f}, 17 \mathrm{~m}, 26 \mathrm{~m})$, quatro -7 vezes $(23,3 \%$ $\pm 7,7-$ Obs. 2f, 4f, 9f, 11m, 19m, 20f $22 f)$, dois - 6 vezes $(20,0 \% \pm 7,3-$ Obs. $8 \mathrm{f}, 12 \mathrm{f}, 21 \mathrm{f}, 23 \mathrm{~m}, 24 \mathrm{~m}, 25 \mathrm{~m}$ ), cinco - 6 vezes $(20,0 \% \pm 7,3$ - Obs. $5 \mathrm{f}, 7 \mathrm{f}, 14 \mathrm{~m}$, $27 \mathrm{~m}, 29 \mathrm{~m}, 30 \mathrm{~m}), \mathrm{um}-2$ vezes $(6,7 \%$ $\pm 4,6$ - Obs. $18 \mathrm{f}, 28 \mathrm{~m})$, seis - 1 vez $(3,3 \%$ $\pm 3,3-$ Obs. $10 \mathrm{~m})$ e sete -1 vez $(3,3 \%$ $\pm 3,3-$ Obs. $13 \mathrm{~m}$ ).

Aduzimos que os afluentes do ducto principal (de Wirsung) - considerado o sentido (proximal-distal) do fluxo excretório - alcançam-no, quase sempre $(90,0 \% \pm$ $5,5)$, pelo contorno lateral direito ou esquerdo; em poucos casos $(10,0 \% \pm 5,5-$ Obs. 4f, 21f, 28m), registramos um dos coletores com abertura ventral - 2 vezes $(6,7 \% \pm 4,6$ - Obs. 4f, 21f) ou dorsal - 1 vez $(3,3 \% \pm 3,3$ - Obs. $28 \mathrm{~m})$.

Informamos ainda que, em 6 pâncreas $(20,0 \% \pm 7,3-$ Obs. $7 \mathrm{f}, 10 \mathrm{~m}, 15 \mathrm{~m}, 21 \mathrm{f}$

\footnotetext{
* Essas 30 peças integraram, juntamente com 30 separadas de equinos e 30 , de asininos, material que serviu à análise das comunicaçōes do sistema excretor do pâncreas com o duodeno, objeto de publicação anterior (SANTIS PRADA, FERNANDES FILHO \& BORELLI $-1970)$.
} 
PRADA, I. L. de S. et al. - Contribuição ao estudo do sistema excretor do pâncreas em muares (Equus caballus x Equus asinus). Rev. Fac. Med. vet. Zootec. Univ. S. Paulo, 11: 271-93, 1974.

$25 \mathrm{~m}, 27 \mathrm{~m})$, um dos tributários do ducto principal (de Wirsung) mostra-se conspícuo (Fig. 10), colocando-se à direita -3 vezes $(10,0 \% \pm 5,5$ - Obs. $7 \mathrm{f}, 10 \mathrm{~m}, 15 \mathrm{~m})$ e à esquerda -3 vezes $(10,0 \% \pm 5,5$ Obs, $21 \mathrm{f}, 25 \mathrm{~m}, 27 \mathrm{~m}$ ).

B - O ducto do lobo direito (Figs. 1, $5,6,7,9)$, representando o mais importante coletor da região, origina-se na extremidade caudal dessa massa glandular, em 26 dos 30 pâncreas estudados $(86,7 \%$ 土 6,2 - Obs. 2f, 3f, 4f, 5f, 6f, 7f, 8f, 9f, $10 \mathrm{~m}, 11 \mathrm{~m}, 13 \mathrm{~m}, 14 \mathrm{~m}, 16 \mathrm{f}, 17 \mathrm{~m}, 18 \mathrm{f}, 19 \mathrm{f}$ 20f, 21f, $22 \mathrm{f}, 23 \mathrm{~m}, 24 \mathrm{~m}, 26 \mathrm{~m}, 27 \mathrm{~m}, 28 \mathrm{~m}$, $29 \mathrm{~m}, 30 \mathrm{~m}$ - Fig. 1); nas outras 4 preparações $(13,3 \% \pm 6,2$ - Obs. 1f, 12f, 15m, $25 \mathrm{~m}$ - Fig. 5), ele provém do lobo esquerdo, percorre-o em parte e estabelece, em 2 delas $(6,7 \% \pm 4,6$ - Obs. 12f, $15 \mathrm{~m})$, anastomose com o ducto do lobo esquerdo. Por intermédio da ponte de tecido situada caudalmente ao anel portal, atinge finalmente o território que lhe é próprio. Termina por associar-se ao ducto do lobo esquerdo para constituir o ducto principal (de Wirsung). Ao atravessar o lobo direito, recebe muitos afluentes (Fig. 3), ou seja: onze -6 vezes $(20,0 \% \pm 7,3-$ Obs. 1f, $14 \mathrm{~m}, 16 \mathrm{f}, 19 \mathrm{~m}, 21 \mathrm{f}, 23 \mathrm{~m})$, dez -5 vezes $(16,7 \% \pm 6,8-$ Obs. $5 \mathrm{f}, 9 \mathrm{f}, 12 \mathrm{f}, 22 \mathrm{f}$, $26 \mathrm{~m})$, nove -4 vezes $(13,3 \% \pm 6,2$

Obs. $3 \mathrm{f}, 11 \mathrm{~m}, 20 \mathrm{f}, 24 \mathrm{~m}$ ), oito -3 vezes $(10,0 \% \pm 5,5-$ Obs. $6 f, 7 f, 18 f)$, doze 3 vezes $(10,0 \% \pm 5,5-$ Obs. $8 \mathrm{f}, 17 \mathrm{~m}, 25 \mathrm{~m})$, seis - 2 vezes $(6,7 \% \pm 4,6-$ Obs. $15 \mathrm{~m}$, $29 \mathrm{~m})$, sete -2 vezes $(6,7 \% \pm 4,6-$ Obs. 2f, 4f), cinco -1 vez $(3,3 \% \pm 3,3$ - Obs. $27 \mathrm{~m})$, treze - 1 vez $(3,3 \% \pm 3,3$ - Obs. $30 \mathrm{~m})$, catorze -1 vez $(3,3 \% \pm 3,3$ - Obs. $10 \mathrm{~m})$, quinze - 1 vez $(3,3 \% \pm$ $3,3$ - Obs. $13 \mathrm{~m})$ e dezesseis - 1 vez $(3,3 \% \pm 3,3$ - Obs. $28 \mathrm{~m})$.

Esclarecemos que os citados tributários do ducto do lobo direito nele se lançam, quase sempre, lateralmente, à direita ou à esquerda; encontramos ,todavia, entre eles, um com abertura dorsal -8 vezes
$(26,7 \% \pm 8,1$ - Obs. 3f, $6 \mathrm{f}, 7 \mathrm{f}, 11 \mathrm{~m}, 13 \mathrm{~m}$, $14 \mathrm{~m}, 17 \mathrm{~m}, 19 \mathrm{~m})$ e ventral $-1 \mathrm{vez}(3,3 \%$ $\pm 3,3$ - Obs. $8 \mathbf{f}$ ).

Registramos ainda que, em 15 das 26 focadas glândulas $(50,0 \% \pm 9,1$ - Obs. $3 \mathrm{f}, 6 \mathrm{f}, 7 \mathrm{f}, 8 \mathrm{f}, 10 \mathrm{~m}, 11 \mathrm{~m}, 12 \mathrm{f}, 13 \mathrm{~m}, 15 \mathrm{~m}$, $18 \mathrm{f}, 19 \mathrm{~m}, 26 \mathrm{~m}, 27 \mathrm{~m}, 30 \mathrm{~m}$ ), alguns dos afluentes do ducto do lobo direito surgem conspícuos, isto é, um vindo da direita - 11 vezes $(36,7 \% \pm 8,7-$ Obs. $3 \mathrm{f}, 7 \mathrm{f}, 8 \mathrm{f}, 10 \mathrm{~m}$, $11 \mathrm{~m}, 12 \mathrm{f}, 13 \mathrm{~m}, 15 \mathrm{~m}, 18 \mathrm{f}, 27 \mathrm{~m}, 30 \mathrm{~m}$ ), um da esquerda -3 vezes $(10,0 \% \pm 5,5$ - Obs. $6 \mathrm{f}, 19 \mathrm{~m}, 29 \mathrm{~m})$ e um de cada lado -1 vez $(3,3 \% \pm 3,3-$ Obs. $26 \mathrm{~m})$.

Tal como referimos, em 4 órgãos (13,3\% $\pm 6,2$ - Obs. 1f, 12f, 15m, 25m - Figs. 3 , 5), ao ducto do Iobo direito vêm ter, também, coletores originários da porção caudal do lobo esquerdo, a saber: seis 2 vezes $(6,7 \% \pm 4,6-$ Obs. $12 \mathrm{f}, 25 \mathrm{~m})$, quatro -1 vez $(3,3 \% \pm 3,3-$ Obs. $15 \mathrm{~m})$ e oito -1 vez $(3,3 \% \pm 3,3$ - Obs. 1f); em 3 destes casos $(10,0 \% \pm 5,5$ - Obs. 1f, $15 \mathrm{~m}, 25 \mathrm{~m}$ ), um dos afluentes do lobo esquerdo apresenta-se conspícuo.

C - O ducto do lobo esquerdo (Figs. $1,5,6,7,9)$ configura a mais importante via de escoamento da região e termina sempre por associar-se ao ducto do lobo direito para constituir o ducto principal (de Wirsung); provém da extremidade caudal de seu território, em 26 das 30 glândulas dissecadas $(86,7 \% \pm 6,2$ - Obs. $2 \mathrm{f}$, $3 f, 4 f, 5 f, 6 f, 7 f, 8 f, 9 f, 10 m, 11 m, 13 m$, $14 \mathrm{~m}, 16 \mathrm{f}, 17 \mathrm{~m}, 18 \mathrm{f}, 19 \mathrm{f}, 20 \mathrm{f}, 21 \mathrm{f}, 22 \mathrm{f}, 23 \mathrm{~m}$, $24 \mathrm{~m}, 26 \mathrm{~m}, 27 \mathrm{~m}, 28 \mathrm{~m}, 29 \mathrm{~m}, 30 \mathrm{~m}$ - Fig. 1) pois, nas mais $4(13,3 \% \pm 6,2-$ Obs. If, $12 \mathrm{f}, 15 \mathrm{~m}, 25 \mathrm{~m}$ - Fig. 5), o ducto do lobo direito responsabiliza-se também pela drenagem dessa região. Durante seu percurso, o ducto do lobo esquerdo recebe numerosas contribuições, em diferentes arranjos (Fig. 4), isto é: treze -6 vezes $(20,0 \% \pm 7,3$ - Obs. $5 \mathrm{f}, 8 \mathrm{f}, 11 \mathrm{~m}, 17 \mathrm{~m}$, 
PRADA, I. L. de S. et al. - Contribuição ao estudı do sistema excretor do pâncreas em muares (Equus caballus $\mathrm{x}$ Equus asinus). Rev, Fac. Med. vet. Zootec. Univ. S. Paulo, 11: $271-93,1974$.

$28 \mathrm{~m}, 30 \mathrm{~m})$, doze -4 vezes $(13,3 \% \pm 6,2$ - Obs. 2f, 3f, $24 \mathrm{~m}, 29 \mathrm{~m})$, dezesseis -4 vezes $(13,3 \% \pm 6,2$ - Obs. $4 \mathrm{f}, 7 \mathrm{f}, 16 \mathrm{f}$, $22 \mathrm{f})$, dezenove -3 vezes $(10,0 \% \pm 5,5$ - Obs. 9f, 21f, 26m), onze - 2 vezes $(6,7 \% \pm 4,6$ - Obs. 12f, $14 \mathrm{~m})$, catorze 2 vezes $(6,7 \% \pm 4,6$ - Obs. 6f, 18f), quinze -2 vezes $(6,7 \% \pm 4,6-$ Obs. $10 \mathrm{~m}$, $19 \mathrm{~m})$, dezessete -2 vezes $(6,7 \% \pm 4,6-$ Obs. $23 \mathrm{~m}, 27 \mathrm{~m})$, cinco -1 vez $(3,3 \% \pm$ $3,3$ - Obs. $25 \mathrm{~m})$, sete -1 vez $(3,3 \% \pm$ $3,3$ - Obs. $7 \mathrm{f})$, nove -1 vez $(3,3 \% \pm$ $3,3$ - Obs. $15 \mathrm{~m})$, dezoito -1 vez $(3,3 \%$ $\pm 3,3$ - Obs. 20f) e vinte e quatro -1 vez $(3,3 \% \pm 3,3-$ Obs. $13 \mathrm{~m})$.

Os afluentes do ducto do lobo esquerdo alcançam-no, quase sempre, pelo contorno direito ou esquerdo. Entretanto, evidenciamos, entre eles, com abertura dorsal, um -4 vezes $(13,3 \% \pm 6,2$ - Obs. $8 \mathrm{f}, 12 \mathrm{f}, 17 \mathrm{~m}, 20 \mathrm{f})$ ou dois -3 vezes $(10,0 \%$ $\pm 5,5-$ Obs. $18 \mathrm{f}, 23 \mathrm{~m}, 27 \mathrm{~m}$ ) e ventral, um - 1 vez $(3,3 \% \pm 3,3-$ Obs. $4 \mathrm{f})$.

Verificamos também que, em $\mathbf{1 1}$ das disseç̧ões $(36,7 \% \pm 8,7-$ Obs. 2f, 8f, 9f, $10 \mathrm{~m}, 11 \mathrm{~m}, 14 \mathrm{~m}, 20 \mathrm{f}, 24 \mathrm{~m}, 26 \mathrm{~m}, 29 \mathrm{~m}, 30 \mathrm{~m}$ ), alguns dos coletores tributários do ducto do lobo esquerdo mostram-se conspícuos, vale dizer, um a esquerda -8 vezes $(26,7 \% \pm$ 7,3 - Obs. $8 \mathrm{f}, 9 \mathrm{f}, 10 \mathrm{~m}, 11 \mathrm{~m}, 14 \mathrm{~m}, 20 \mathrm{f}$, $24 \mathrm{~m}, 30 \mathrm{~m})$, um a direita -2 vezes $(6,7 \%$ $\pm 4,6$ - Obs. $2 \mathrm{f}, 29 \mathrm{~m})$ e um de cada lado -1 vez $(3,3 \% \pm 3,3-$ Obs. $26 \mathrm{~m})$.

Informamos, finalmente, a ocorrência de via anastomótica, ora mais, ora menos calibrosa, a interligar, servindo-se da ponte, os ductos dos lobos direito e esquerdo, em apenas 4 órgãos $(13,3 \% \pm 6,2$ - Obs. 6f, $12 \mathrm{f}, 15 \mathrm{~m}, 17 \mathrm{~m}$ - Figs. 5, 6, 7).

D - O ducto acessório (de Santorini) - (Figs. 5, 8, 9, 10), presente em todos os casos, percorre massa glandular restrita, incompletamente separada da face ventral do corpo do pâncreas por plano de tecido conjuntivo.

Por intermédio de sua extremidade central, o ducto acessório (de Santorini) relaciona-se sempre com o sistema do ducto principal (de Wirsung), melhor explicando, prende-se diretamente nele - 17 vezes $(56,7 \% \pm 9,0$ - Obs. 1f, 3f, 4f, 5f, 6f, $7 \mathrm{f}, 11 \mathrm{~m}, 13 \mathrm{~m}, 15 \mathrm{~m}, 17 \mathrm{~m}, 20 \mathrm{f}, 22 \mathrm{f}, 23 \mathrm{~m}$, $27 \mathrm{~m}, 28 \mathrm{~m}, 29 \mathrm{~m}, 30 \mathrm{~m}$ - Fig. 8 ), no ducto do lobo esquerdo - 6 vezes $(20,0 \%$ 上 7,3 - Obs. $8 \mathrm{f}, 10 \mathrm{~m}, 12 \mathrm{f}, 16 \mathrm{f}, 19 \mathrm{~m}, 24 \mathrm{~m}-$ Fig. 5), no ducto do lobo direito -2 vezes $(6,7 \% \pm 4,6$ - Obs. 9f, 14m - Fig. 9) ou em afluente conspicuo do primeiro ducto -2 vezes $(6,7 \% \pm 4,6-$ Obs. $21 \mathrm{f}$, $25 \mathrm{~m}$ - Fig. 10), do terceiro - 2 vezes $(6,7 \% \pm 4,6-$ Obs. $18 \mathrm{f}, 26 \mathrm{~m})$ e do segundo - 1 vez $(3,3 \% \pm 3,3$ - Obs. $2 f)$. Pela extremidade oposta, o ducto acessório (de Santorini) avizinha-se do duodeno e, independentemente da presença de papila, alcança-o em 24 das 30 dissecçōes $(80,0 \%+7,3$-Obs. 2f, 4f, 5f, 6f, 7f, $8 \mathrm{f}, 9 \mathrm{f}, 10 \mathrm{~m}, 11 \mathrm{~m}, 12 \mathrm{f}, 13 \mathrm{~m}, 14 \mathrm{~m}, 15 \mathrm{~m}, 16 \mathrm{f}$, $17 \mathrm{~m}, 18 \mathrm{f}, 19 \mathrm{~m}, 23 \mathrm{~m}, 24 \mathrm{~m}, 25 \mathrm{~m}, 27 \mathrm{~m}, 28 \mathrm{~m}$, $29 \mathrm{~m}, 30 \mathrm{~m})$; embora em 9 delas $(30,0 \%$ $\pm 8,4-$ Obs. $10 \mathrm{~m}, 13 \mathrm{~m}, 15 \mathrm{~m}, 16 \mathrm{f}, 23 \mathrm{~m}$, $24 \mathrm{~m}, 25 \mathrm{~m}, 28 \mathrm{~m}, 29 \mathrm{~m}$ ), nem o ar nem a massa injetados no sistema tenham chegado, através dela, à luz intestinal.

O ducto acessório (de Santorini) recebe, ao longo de seu trajeto, inúmeros tributários (Fig. 11), ou seja: quatro - 11 vezes $(36,7 \% \pm 8,7$ - Obs. 1f, 5f, 7f, 12f, $18 \mathrm{f}, 19 \mathrm{~m}, 21 \mathrm{f}, 22 \mathrm{f}, 26 \mathrm{~m}, 28 \mathrm{~m}, 29 \mathrm{~m})$, três -8 vezes $(26,7 \% \pm 8,1$ - Obs. $3 f, 4 f, 8 f$, $9 \mathrm{f}, 15 \mathrm{~m}, 17 \mathrm{~m}, 27 \mathrm{~m}, 30 \mathrm{~m})$, cinco -4 vevezes $(13,3 \% \pm 6,2-$ Obs. $11 \mathrm{~m}, 20 \mathrm{f}$, $23 \mathrm{~m}, 25 \mathrm{~m})$, dois -2 vezes $(6,7 \% \pm 4,6$ - Obs. 16f, 24m), seis - 2 vezes $(6,7 \% \pm$ $4,6$ - Obs. 2 f, $10 \mathrm{~m})$, sete -2 vezes $(6,7 \%$ $\pm 4,6$ - Obs. $6 \mathrm{f}, 13 \mathrm{~m})$ e oito -1 vez $(3,3 \% \pm 3,3-$ Obs. $14 \mathrm{~m})$. 
PRADA, I. L. de S. et al. - Contribuiçăo ao estudo do sistema excretor do pancreas em muares (Equus caballus $\mathrm{x}$ Equus asinus). Rev. Fac. Med. vet. Zootec. Univ. S. Paulo, 11 271-93, 1974.

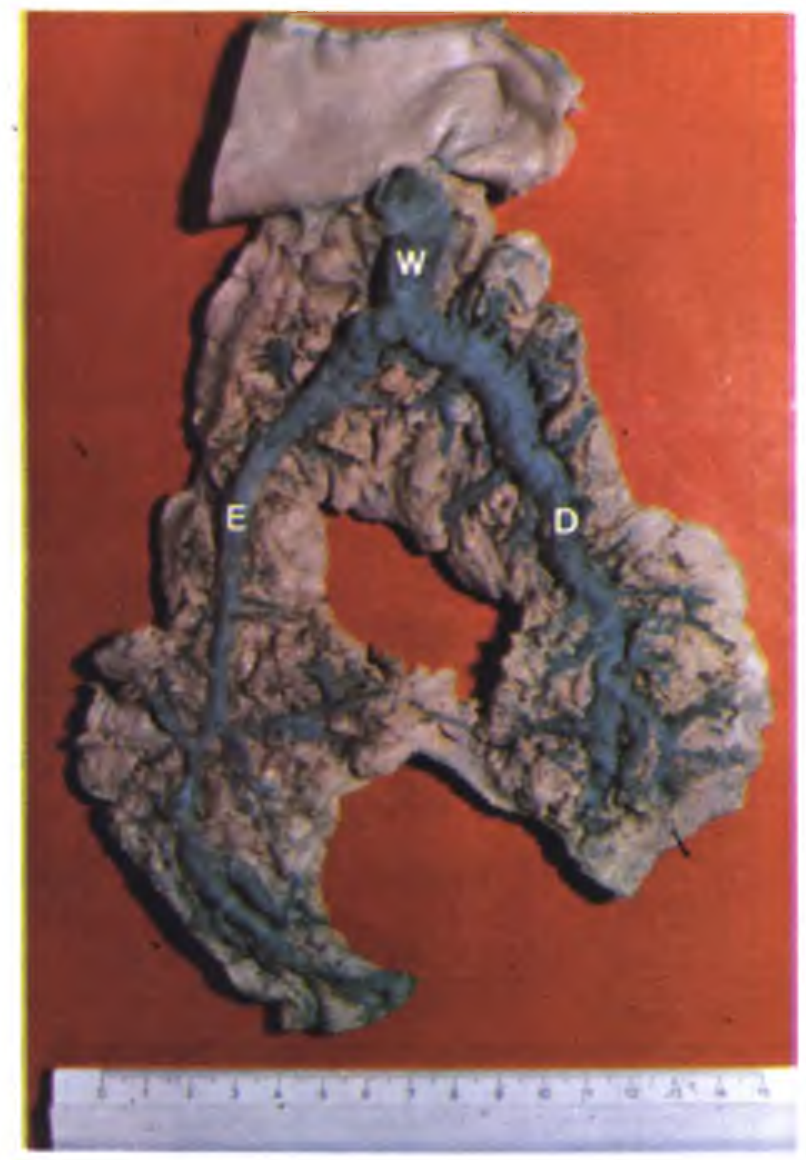

Fig. 1 - Sistema excretor do påncreas (face dorsal) de muar adulto, macho (Obs. 28). O ducto principal (de Wirsung) - (W), às vezes multo curto, resulta sempre da confluência de duas raizes, representadas pelo ducto do lobo direito (D) e ducto do lobo esquerdo (E). 
PRADA, I. L. de S. et al. - Contribuiçāo ao estudo do sístema excretor do pâncreas em muares (Equus caballus $\mathrm{x}$ Equus asinus). Rev. Fac. Med. vet. Zootec. Univ. S. Paulo, 11: 271-93, 1974.

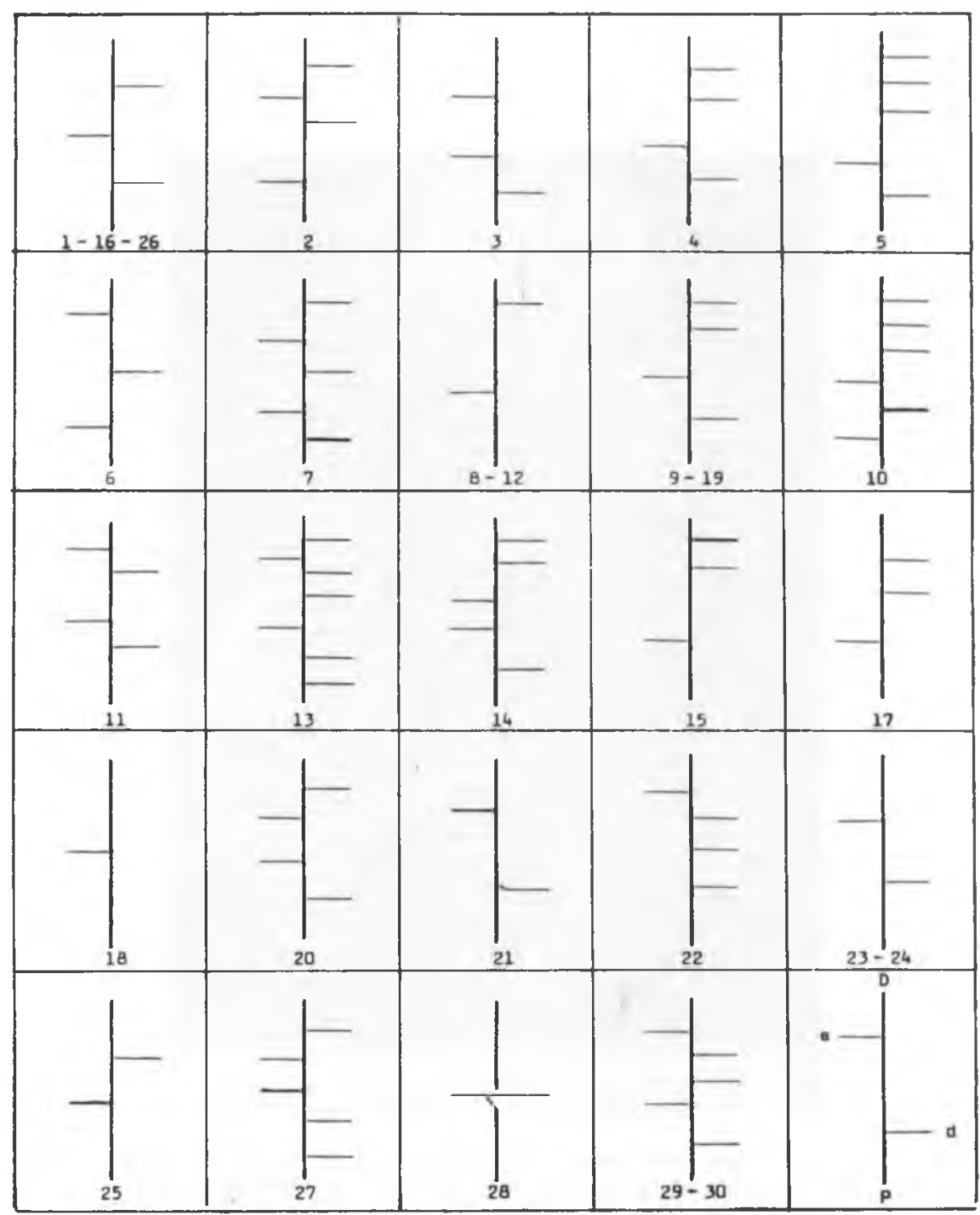

Fig. 2 - (Obs. 11 a $30 \mathrm{~m}$, correspondentes aos números indicados). Esquemas das disposicōes conflguradas pelos tributários do ducto princlpal (de Wirsung), em pâncreas (face dorsal) de muares adultos, machos e 1émeas. Os coletores consplcuos são destacados por tracos mais grossos. P-D - extremidades proximal e distal do ducto principal (de Wlrsung); e-d - coletores procedentes dos lados esquerdo e direito do corpo da glándula. 
PRADA, I. L. de S. et al. - Contribuição ao estudo do sistema excretor do påncreas em muares (Equus caballus $\times$ Equus asinus). Rev. Fac. Med. vet. Zootec. Univ. S. Paulo, 11: 271-93, 1974.

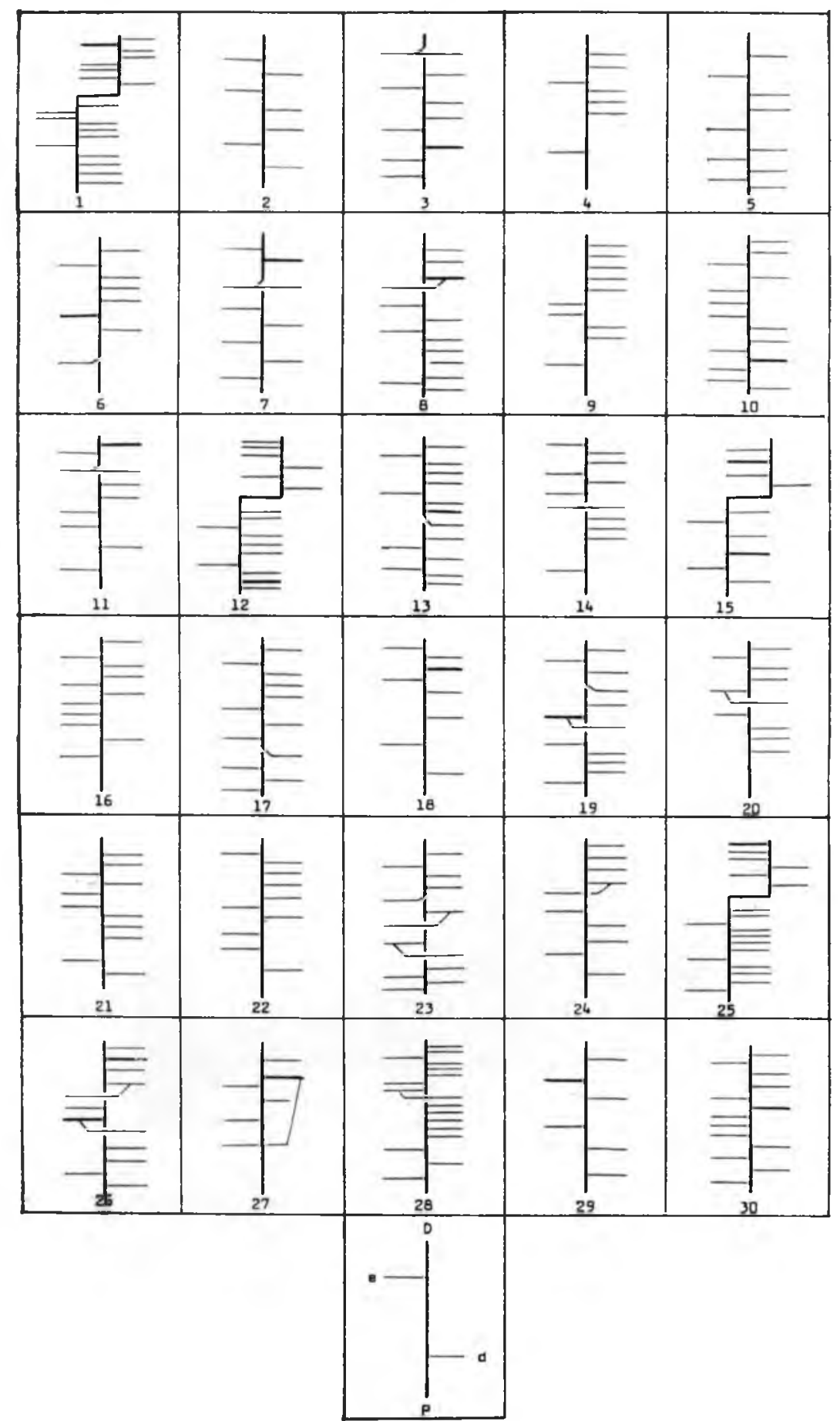

Fig. 3 - (Obs. If a $30 \mathrm{~m}$, correspondentes aos números indlcados). Esquemas das disposisōes conflguradas pelos afluentes do ducto do lobo dlrelto, em pâncreas (face dorsal) de muares adultos, machos e remeas. Os tributários conspicuos sāo destacados por traços mals grossos. P-D - extremidades proximal e distal do ducto do lobo direlto; e-d - coletores procedentes dos lados esquerdo e direito do lobo direito da glåndula. 
PRADA, I. L de $\mathrm{S}$. et al. - Contribuição ao estudo do sistema excretor do pâncreas em muares (Equus caballus $x$ Equus asinus). Rev. Fac. Med. vet. Zootec. Univ. S. Paulo, 11: $271-93,1974$.

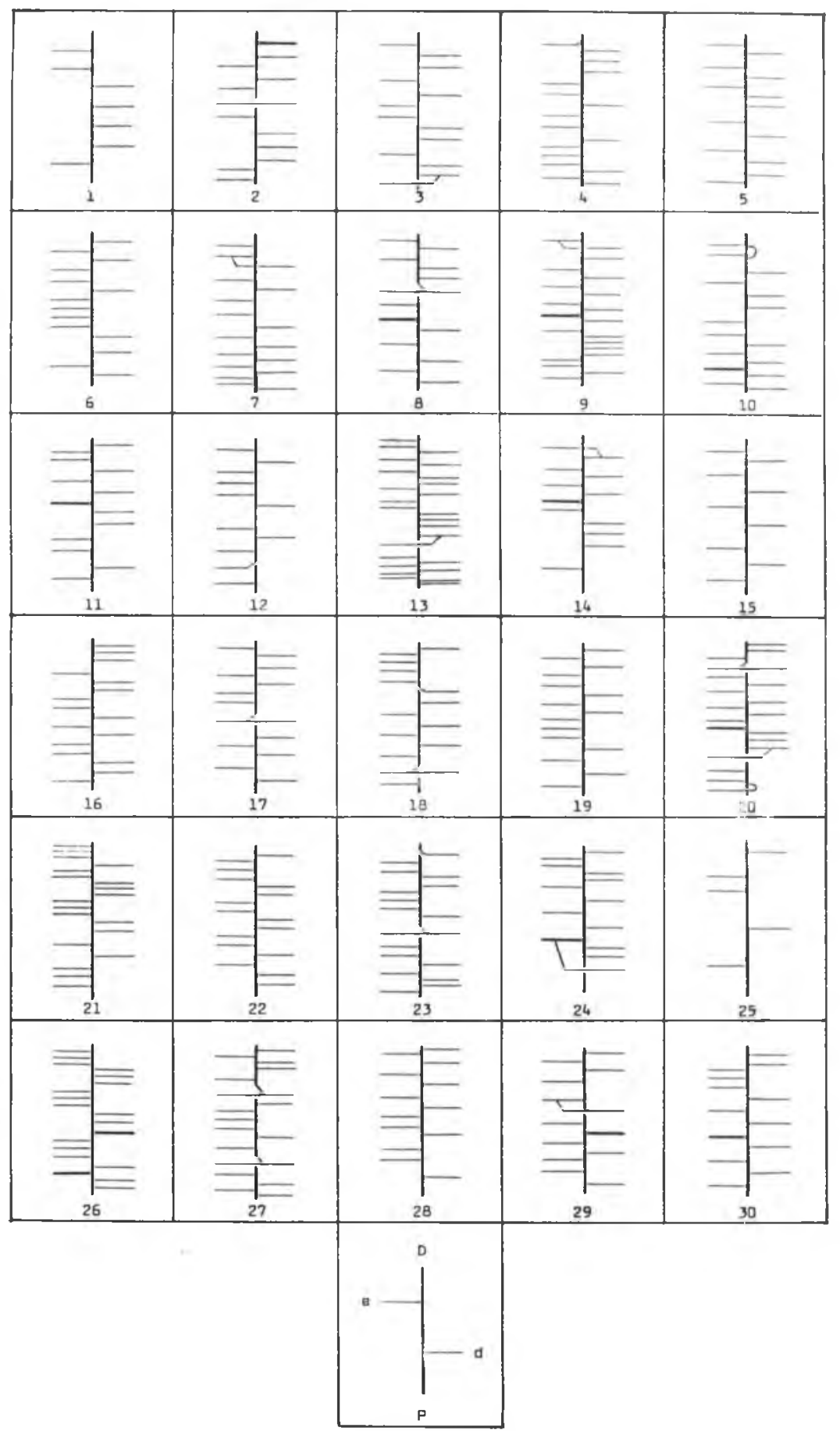

Fig. 4 - (Obs. If a 30m, correspondentes aos números indicados). Esquemas das disposicóes configuradas pelos tributários do ducto do lobo esquerdo, em påncreas (face dorsal) de muares adultos, machos e fêmeas. Os coletores conspicuos são destacados por traços mais grossos. P-D - extremidades proximal e distal do ducto do lobo esquerdo; e-d coletores procedentes dos lados escuerdo e direito do lobo esquerdo da glândula. 
PRADA, I. L. de S. et al. - Contribuição ao estudo do sistema excretor do pâncreas em muares (Equus caballus $\mathrm{x}$ Equus asinus). Rev. Fac. Med. vet. Zootec. Univ. S. Paulo, 11: 271-93, 1974 .

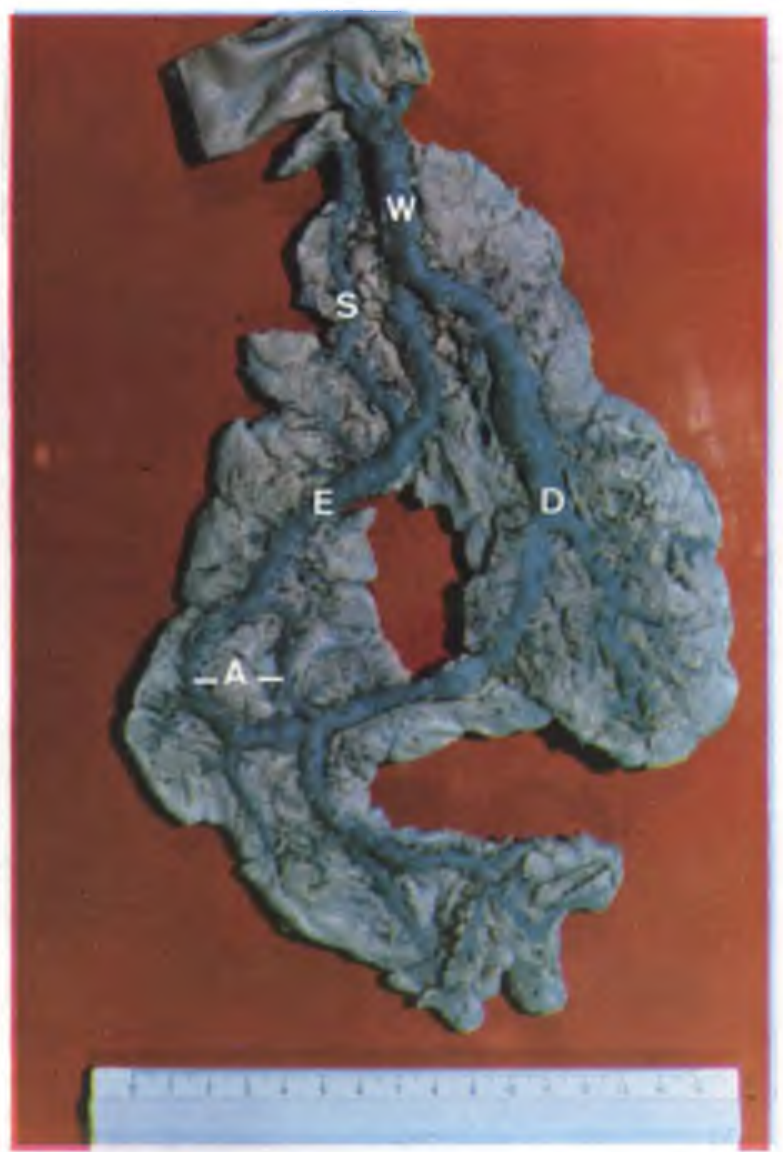

Fig. 5 - Em 13,3\% das glândulas nissecadas (face dorsal), pertencentes a muares adultos, machos e feemeas, o ducto do lobo direito (D) acolhe tributários da porcão caudal do lobo esquerdo e estabelece,em $6,7 \%$ delas, anastomose (A) com o ducto dessa regiāo (E). O ducto acessório (de Santorini) - (S) é vísto, como acontece em $20.0 \%$ dos casos, a prender-se no ducto do lobo esquerdo (E). w - ducto principal (de Wirsung). 
PRADA, I. L. de S. et al. - Contribuição ao estudo do sistema excretor do pancreas em muares (Equus caballus $\mathrm{x}$ Equus asinus). Rev. Fac. Med. vet. Zootec. Univ. S. Paulo, 11: 271-93, 1974.

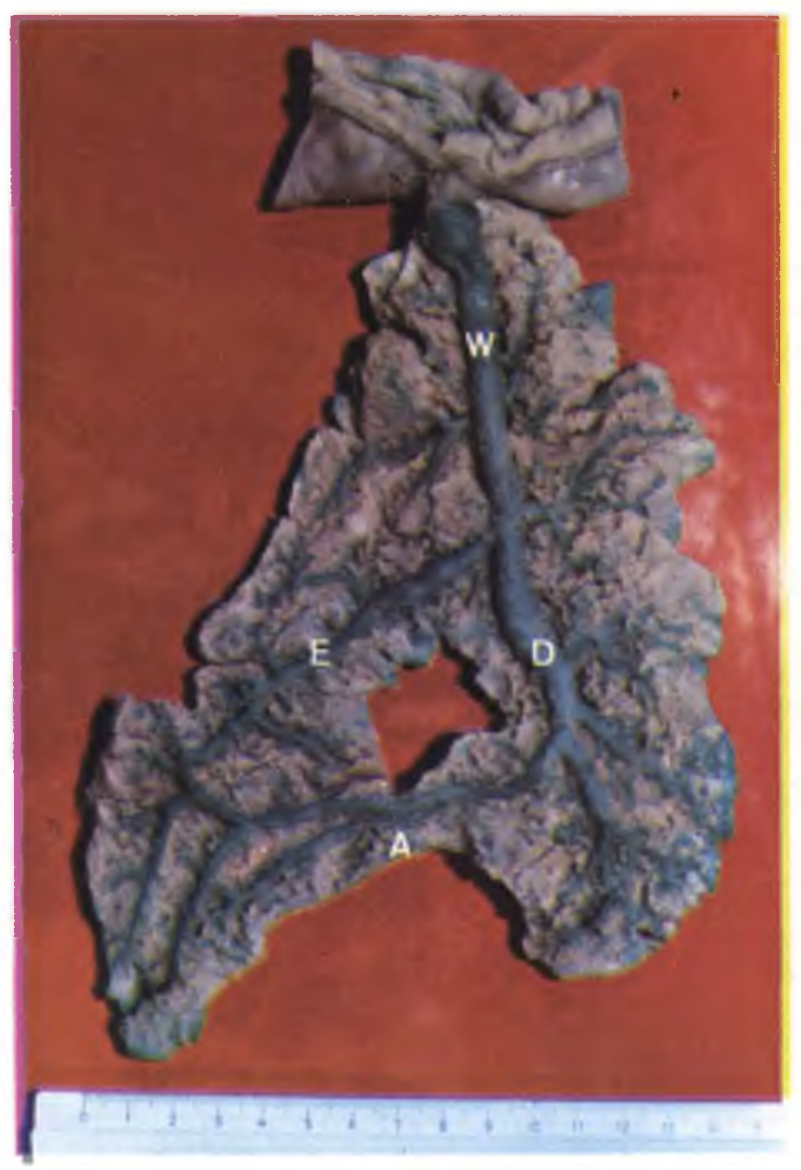

Fig. 6 - Sistema excretor do păncreas (face dorsal) de muar adulto, fêmea (Obs. 6). O ducto principal (de Wlrsung) - (W). de comprimento variável, constitui-se pela uniāo do ducto do lobo direlto (D) e ducto do lobo esquerdo (E), os quais se anastomosam (A) servindo-se da ponte, em $13,3 \%$ das preparaços. 
PRADA, I. L. de S. et al. - Contribuicāo ao estudo do sistema excretor do páncreas em muares (Equus caballus $\mathrm{x}$ Equus asinus). Rev. Fac. Ned. vet. Zootec. Univ. S. Paulo, 11: 271-93, 1974 .

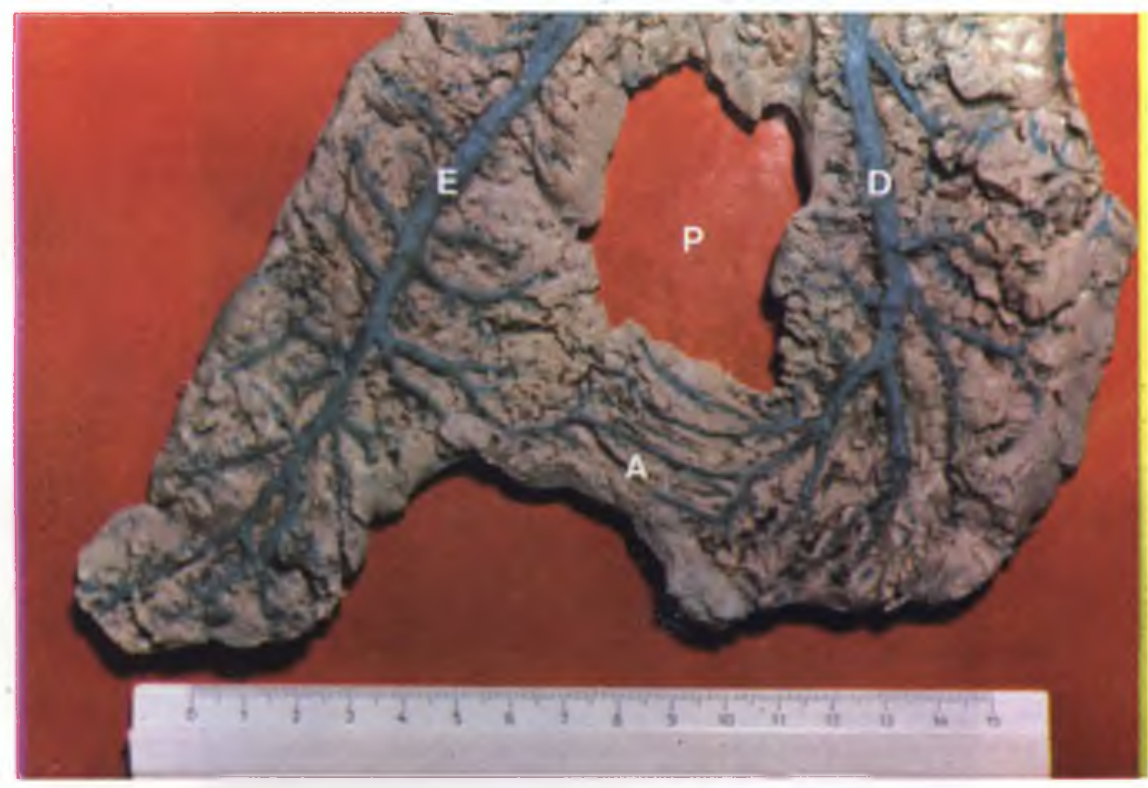

Fig. 7 - $O$ ducto do lobo direito (D) e o ducto do lobo esquerdo (E) interligam-se mediante via anastomótica (A), ora maís ora menos calibrosa, que percorre ponte de tecldo colocada caudalmente ao anel portal (P), em 13,3\% dos pancreas dissecadas (face dorsal), pertencentes a muares adultos, machos e femeas. 
PRADA, I. L. de S. et al. - Contribuição ao estudo do sistema excretor do pâncreas em muares (Equus caballus x Equus asinus). Rev. Fac. Med. vet. Zootec. Univ. S. Paulo, 11: 271-93, 1974 .

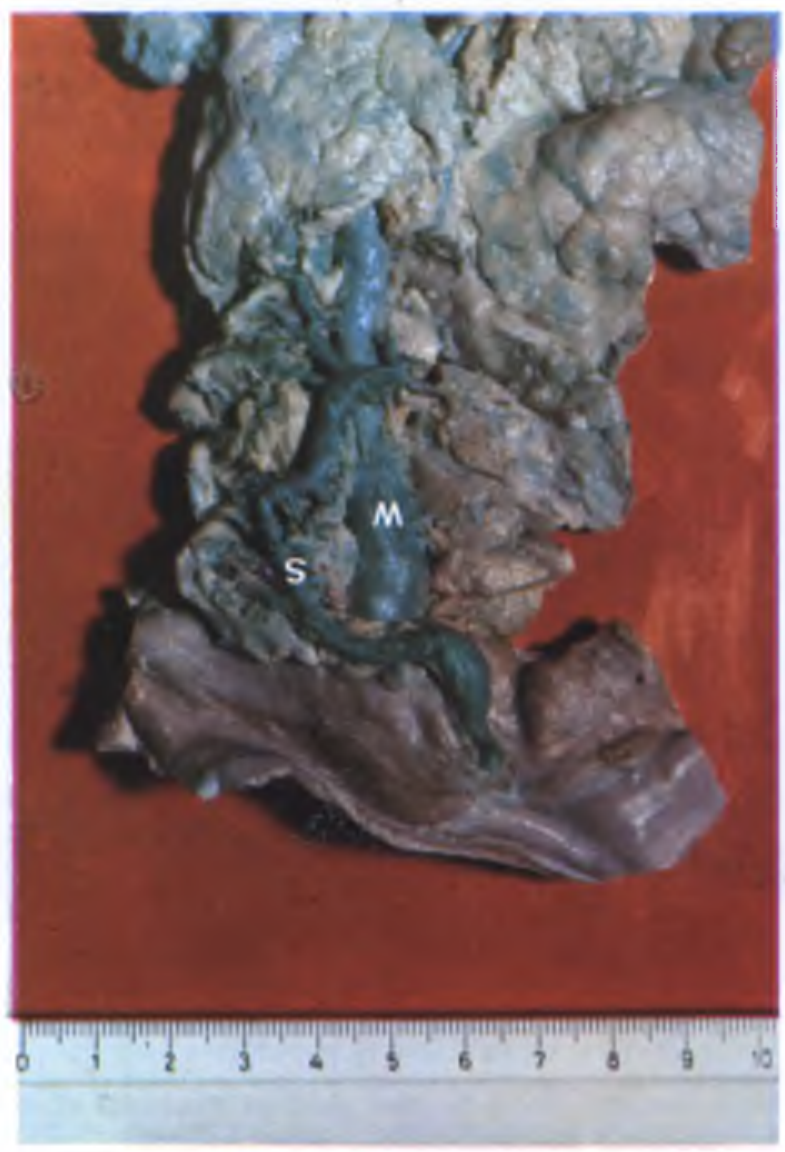

Fig. 8 - O ducto acessório (de Santorini) - (S) associa-se diretamente, por sua extremidade central, em $56,7 \%$ dos pånereas dissecados (face ventral), pertencentes a muares adultos, machos e fêmeas, ao ducto principal (de Wirsung) - (W). 
PRADA, I. L. de S. et al. - Contribulção ao estudo do sistema excretor do pâncreas em muares (Equus caballus $\times$ Equns asinus). Rev. Fac. Med. vet. Zootec. Univ. S. Paulo, 11 : $271-93,1974$.

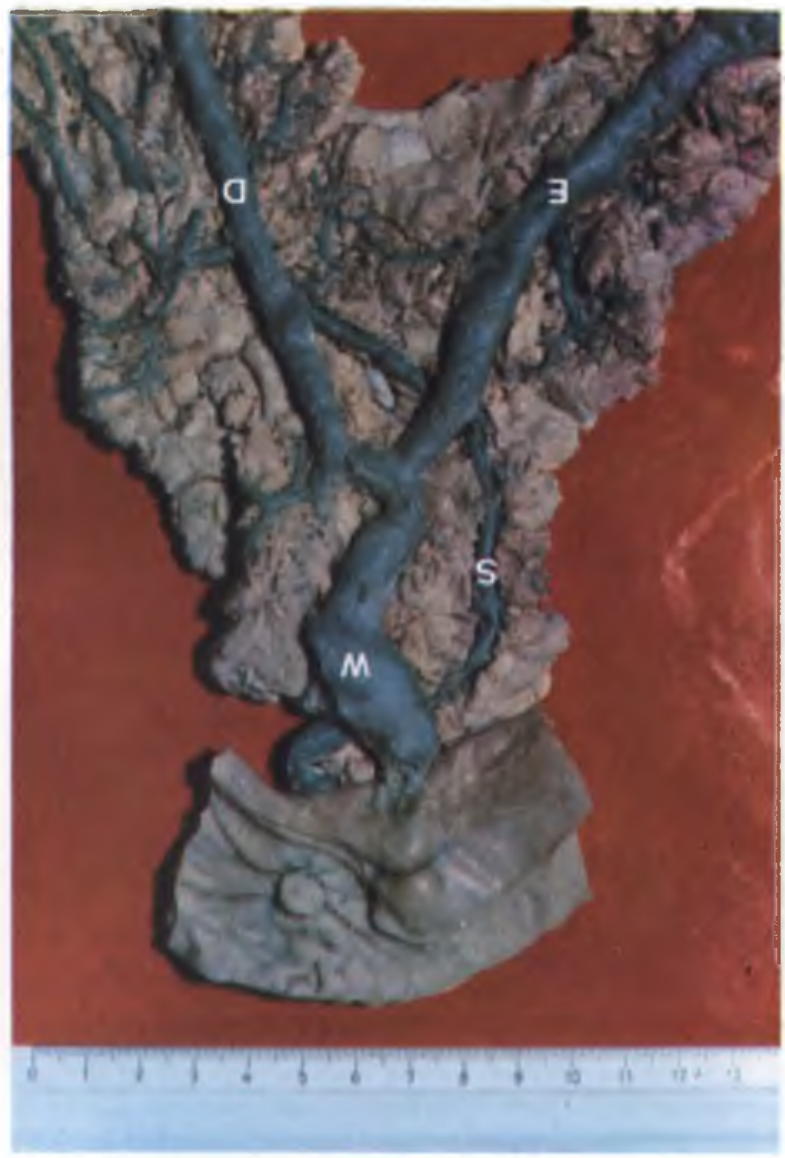

Fig. 9 - Em 6,7\% dos páncreas dissecados (face dorsal) pertencentes a muares adultos, machos e fêmeas, o ducto acessório (de Santorini) - (S) relaciona-se diretamente, por sua extremidade ventral, com o ducto do lobo direito (D). W - ducto principal (de Wirsung); E - ducto do lobo esquerdo. 
PRADA, I. L. de S. et al, - Contribuiçåo ao estudo do sistema excretor do pancreas em mua res (Equus caballus $\mathrm{x}$ Equus asinus). Rev. Rac. Med. vet. Zootec. Univ. S. Paulo, 11 : 271-93, 1974.

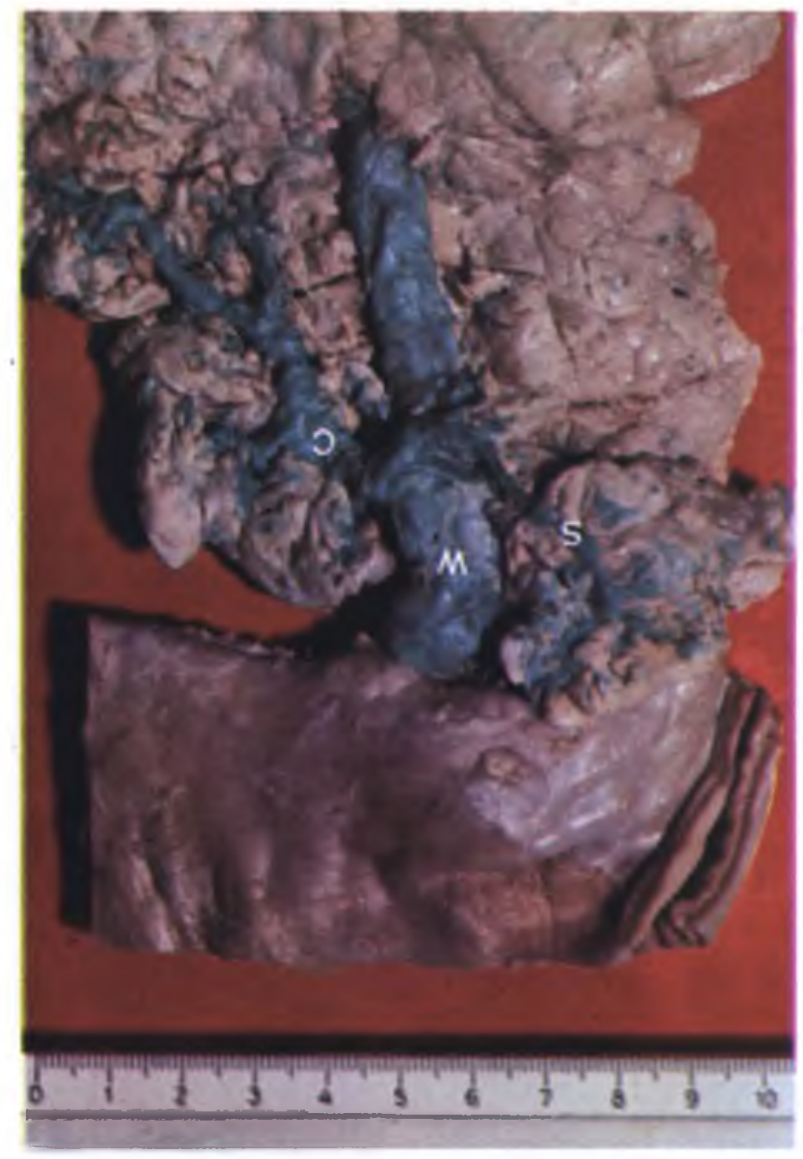

Fig. 10 - 0 ducto acessórlo (de Santorini) - (S) liga-se, por sua extremidade central, a afluente conspicuo (C) do ducto princlpal (de Wirsung) - (W), do ducto do lobo direlto e do ducto do lobo esquerdo, em, respectivamente, $4,6 \%, 4,6 \%$ e $3,3 \%$ dos pâncreas dissecados (face ventral), pertencentes a muares adultos, machos e remeas. 
PRADA, I. L. de S. et al. - Contribuição ao estudo do sistema excretor do pâncreas em muares (Equus caballus $x$ Equus asinus). Rev. Fac. Med. vet. Zootec. Univ. S. Paulo, 11: $271-93,1974$.

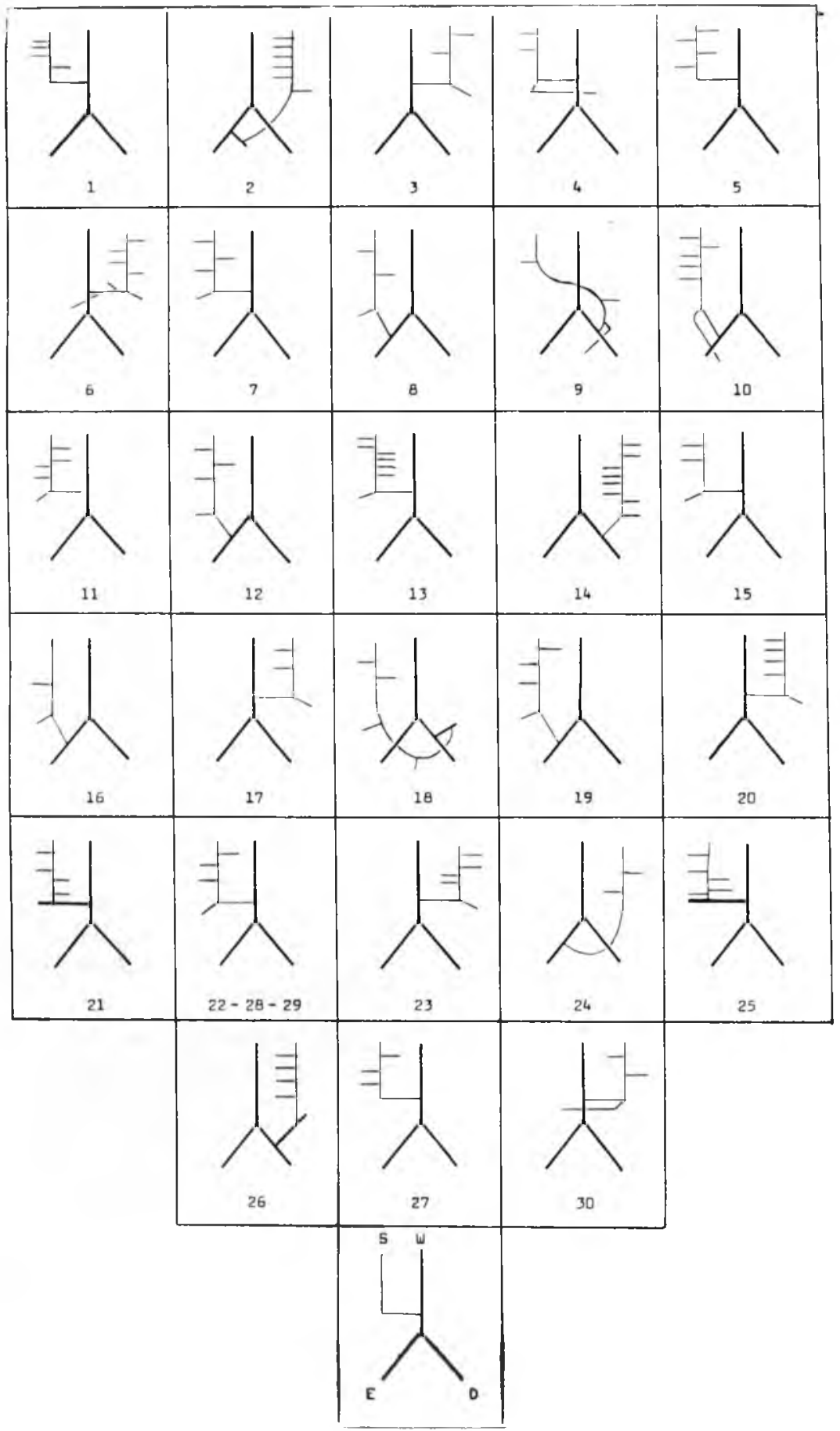

Fig. 11 - (Obs. If a $30 \mathrm{~m}$, corresponacntes aos núnerus indicados). Esquemas das disposiçōes configuradas pelos tributários do ducto acessório (de Santorini) - (S), bem como das comunicaçõcs estabelecidas entre ele e o ducto principal (de Wirsung) — (W), o ducto do lobo direito (D) e o ducto do lobo esquerdo (E). 
PRADA, I. L. de S. et al, - Contribuição ao estudo do sistema excretor do pâncreas em muares (Equus caballus x Equus asinus). Rev. Fac. Med. vet. Zootec. Univ. S. Paulo, 11: $271-93,1974$.

\section{COM ENTARIOS}

Dada a finalidade precípua deste trabalho, e já exposta, efetuaremos com destaque o confronto dos resultados concernentes aos muares com os informes obtidos por PAIVA et al.15 (1973) e PEDUTI NETO 16 (1972) em pesquisas sistemáticas sobre o assunto dedicadas, respectivamente, a equinos e asininos. Por outro lado, sendo as informações exaradas nos livros de texto, suscintas, além de baseadas somente na anatomia dos eqüinos à exceção de BOURDELLE \& BRESSOU 1 (1937) que oferecem descrição única para os eqüídeos -, resta-nos mesmo apontálos no comentário dos aspectos de ordem geral. Assim, focalizando-os inicialmente, anotamos que, conforme indicam ZANOLLI 23 (1910), BRADLEY 2 (1922), SCHMALTZ 20 (1928), ELLENBERGER \& BAUM 5 (1932), BRUNI \& ZIMMERL ${ }^{3}$ (1947), FAVILLI ${ }^{6}$ (1931), GONZALEZ Y GARCIA \& ÁLVAREZ ? (1961), ZIMMERL 24 (1949), SCHUMMER \& NICKEL ${ }^{21}$ (1960), KATO 8 (1961), LESBRE 10 (1922), CARADONNA 4 (1930), MONGIARDINO 12 (1903), MONTANE \& BOURDELLE 13 (1913), LEPOUTRE 9 (1921), BOURDELLE \& BRESSOU ${ }^{1}$ (1937), apesar de nomeá-los diferentemente, encontramos, a integrarem o sistema excretor do pâncreas dos muares, o ducto principal (de Wirsung) e o ducto acessório (de Santorini); estabelecemos contudo a ressalva que este coletor nem sempre alcança a parede duodenal $(80,0 \%)$ podendo, mesmo em o fazendo, deixar de conduzir $(30,0 \%)$ o ar ou a massa nele injetados, para a luz intestinal. Aliás, estes achados de nossa pesquisa - que sucede investigaçōes similares, efetuadas por PRADA et al. 19 (1966), PRADA 17 (1970) e PAIVA et al. ${ }^{14}$ (1972), por ordem em zebuínos, taurinos e búfalos -, completam as verificaçōes anteriormente realizadas por PRADA et al.18 (1970) a respeito da variedade das comunicações do sistema excretor do pâncreas de eqüinos, asininos e muares com o duodeno, talvez ligadas a razões de ordem embriológica, expostas por LORDY 11 (1940).

Ainda no que tange ao comportamento do ducto acessório (de Santorini), assinalamos conexão de sua extremidade central com o ducto principal (de Wirsung), na maior parte das preparações de muares $(56,7 \%)$, tal como referem, para os eqüinos, BRADLEY 2 (1921), LESBRE 10 (1922), CARADONNA 4 (1930), FAVILLI 6 (1931), BOURDELLE \& BRESSOU 1 (1937), GONZALEZ Y GARCIA \& ALVAREZ $^{7}$ (1961), BRUNI \& ZIMMERL ${ }^{3}$ (1947) e SISSON \& GROSSMANN 22 (1965). Mas, conforme anotam ELLENBERGER \& BAUM 5 (1932) para os eqüinos, essa disposição não é de registro constante também entre os muares. De fato, encontramos o ducto acessório (de Santorini) ligado ao ducto do lobo esquerdo $(20,0 \%)$ - arranjo também aludido por BRUNI \& ZIMMERL e SISSON \& GROSSMAN -, ao ducto do lobo direito $(6,7 \%)$ ou a tributário conspícuo do ducto principal (de Wirsung) - $(6,7 \%)$, do ducto do lobo direito $(6,7 \%)$ e do ducto do lobo esquerdo $(3,3 \%)$.

Tendo encontrado sempre o ducto principal (de Wirsung) a narcer da confluência de duas raízes, representadas pelos ductos dos lobos direito e esquerdo, divergimos de GONZALEZ Y GARCIA \& $A L-$ VAREZ $^{7}$ (1961) e concordamos com ZANOLLI 23 (1910), e ainda parcialmente com LESBRE 10 (1922), que as consideram, por ordem, em número de três, duas e duas ou três.

Comparando agora diretamente nossos resultados com os obtidos por PAIVA et al. ${ }^{15}$ (1973) e PEDUTI NETO ${ }^{16}$ (1972), nas pesquisas concernentes, por 
PRADA, I. L. de S. et al. - Contribuicão ao estudo do sistema excretor do pânereas em muares (Equus caballus $\mathrm{x}$ Equus asinus). Rev. Fac. Med, vet. Zootec. Univ. S. Paulo, 11: $271-93,1974$.

ordem, a equinos e asininos, lembramos que a validade deste confronto esteia-se no fato dos diferentes animais examinados integrarem o agrupamento dos eqüídeos e, de outra parte, na razāo dos mencionados AA. valerem-se do mesmo método de estudo que utilizamos e de igual critério na sistematização dos coletores pancreáticos.

No tocante ao ducto principal (de Wirsung), caracteriza-se nos três agrupamentos, a nascer da confluência de duas raízes (ductos dos lobos direito e esquerdo) e a receber, durante o percurso que faz pelo corpo da glândula, variável número de afluentes. Entre eqüinos, asininos e muares, tais afluentes aparecem em valores pouco ou nada díspares, somente nas peças com cinco deles $(20,0 \%-23,3 \%-$ $20,0 \%)$; relativamente às portadores de oito $(3,3 \%-3,3 \%)$ e dez $(3,3 \%-3,3 \%)$ coletores, pertencentes apenas a eqüinos e asininos, torna-se válida a mesma afirmativa. Entretanto, exibem índices às vezes diversos, as preparações que mostram dois $(13,3 \%-3,3 \%-20,0 \%)$, três $(6,7 \%$ $-10,0 \%-23,3 \%)$, quatro $(6,7 \%-16,7 \%$ $-23,3 \%)$, seis $(13,3 \%-20,0 \%-3,3 \%)$ e sete $(20,0 \%-20,0 \%-3,3 \%)$ tributários; idêntica é a situação dos casos com um aferente $(10,0 \%-6,7 \%)$, característicos dos eqüinos e muares. Não oferece possibilidade de discussão, a categoria atinente a treze coletores $(3,3 \%)$, assinalada para os eqüinos, pois sua ocorrência não se registrou entre asininos e muares. Por fim, examinada a presença de contingente conspicuo do ducto principal (de Wirsung) em eqüinos, asininos e muares, observamos que relacionam-se a percentagens muito diferentes $(13,3 \%-40,0 \%-20,0 \%)$.

A seu turno, o ducto do lobo direito, a mais importante via escoadora da região, percorre também a porção caudal do lobo esquerdo, em eqüinos e muares $(6,7 \%$ $13,3 \%)$, fato não registrado para os asininos; recolhe daí, coletores em números variáveis para os dois agrupamentos, vale dizer, por ordem: nove $(3,3 \%)$ e doze $(3,3 \%)$; seis $(6,7 \%)$, quatro $(3,3 \%)$ e oito $(3,3 \%)$. Ao drenar o lobo direito, recebe contribuições várias que, nos eqüinos, asininos e muares, se exibem poucas vezes em freqüências idênticas; assim, entre os primeiros e os últimos, anotamos seis $(6,7 \%$ $-6,7 \%)$ e oito coletores $(10,0 \%-10,0 \%)$, arranjos inexistentes nos pâncreas de asininos. Em outros casos, as percentagens mostram-se semelhantes em dois dos grupos, e divergem da do terceiro, o que verificamos nas glândulas com sete (muares - $6,7 \%$; asininos - $3,3 \%$; eqüinos $13,3 \%$ ), dez (muares - 16,7\%; eqüinos - $20,0 \%$; muares $-6,7 \%$ ) e treze (eqüinos e muares - 3,3\%; asininos - 13,3\%) tributários. Por outro lado, divergem de baixa cifra, de um para outro grupo, as categorias atinentes a nove (eqüinos $6,7 \%$; asininos - 10,0\%; muares $13,3 \%$ ), doze (asininos - 6,7\%; muares - 10,0\%; eqüinos - 13,3\%) e catorze (muares - 3,3\%; eqüinos - 6,7\%; asininos $-10,0 \%$ ) afluentes, se bem que revelem valores distantes, confrontadas as posições extremas. Nas três pesquisas, chegamos também ao conhecimento de tipos comuns a somente dois dos conjuntos de animais,e com indices próximos ou afastados. Tais casos sucedem, por ordem, com as preparaçōes portadoras de cinco (muares $-3,3 \%$; eqüinos $-6,7 \%$ ) e dezesseis (muares - 3,3\%; asininos - 6,7\%) contingentes; onze (eqüinos - 6,7\%; muares - 20,0\%) e quinze (muares - 3,3\%; asininos - 13,3\%) tributários. Resta-nos apontar as disposiçōes características de um só agrupamento, razão que impede confrontos; referem-se aos órgãos com três (eqüinos - 3,3\%), quatro (eqüinos $3,3 \%$ ), dezessete (asininos - 16,7\%), dezoito (asininos - 10,0\%) e dezenove (asininos $-3,3 \%$ ) aferentes. Coletores conspícuos surgem em número de um $(46,7 \%$ $-40,0 \%-46,7 \%)$ ou dois $(40,0 \%-$ $43,3 \%$ - 3,3\%), nos eqüinos, asininos e muares, de três $(3,3 \%-10,0 \%)$, apenas 
PRADA, I. L. de S. et al. - Contribuição ao estudo do sistema excretor do pâncreas em muares (Equus caballus $\mathrm{x}$ Equus asinus). Rev. Fac. Med. vet. Zootec. Univ. S. Paulo, 11: $271-93,1974$.

nos dois primeiros e de quatro $(3,3 \%)$, somente no Equus asinus.

Quanto ao ducto do lobo esquerdo, encontramo-lo, nas três investigações, a percorrer exclusivamente o território que lhe corresponde e recebe, em todas as peças, diversos afluentes. Ressaltamos, de início, que muitas são as categorias registradas em apenas uma das pesquisas, como as referentes a cinco e sete (muares $3,3 \%$ ), dez e vinte e seis (eqüinos - 6,7\% $-3,3 \%$ ), vinte e dois, vinte e sete, vinte e nove e trinta e um (asininos - 3,3\% $3,3 \%-3,3 \%-6,7 \%$ ) contingentes. Por outro lado, somente o arranjo constante de catorze aferentes surge simultaneamente nos três agrupamentos, e com índices diferentes $(10,0 \%-3,3 \%-6,7 \%)$. Na maior parte das vezes, as disposições aparecem em dois dos conjuntos de animais, exibindo percentagens pouco discrepantes. Essa é a condição das peças com nove $(6,7 \%-3,3 \%)$, onze $(3,3 \%-6,7 \%)$, quinze $(10,0 \%-6,7 \%)$, dezesseis $(16,7 \%$ $-13,3 \%)$ e dezessete $(10,0 \%-6,7 \%)$ coletores alusivas a eqüinos e muares; vinte e três $(3,3 \%-6,7 \%)$ tributários, pertencentes a eqüinos e asininos; vinte e quatro contingentes, relativas a asininos e muares. Em muitas ocasiões, verificamos também a ocorrência de tipos comuns a dois grupos que apresentam, contudo, valores distantes. De fato, para eqüinos e muares, assinalamos preparaçōes com doze $(3,3 \%-13,3 \%)$, treze $(3,3 \%-20,0 \%)$ e dezoito $(10,0 \%-3,3 \%)$ coletores; no tocante a asininos e muares, registramos pâncreas portadores de dezenove $(16,7 \%$ - 10,0\%) aferentes; no concernente a eqüinos e asininos, anotamos glândulas a exibirem vinte $(3,3 \%$ - $13,3 \%)$ e vinte e um $(3,3 \%-10,0 \%)$ contingentes. Afinal, tanto em Equus caballus quanto em Equus asinus aparece igual soma de órgãos $(6,7 \%)$ com vinte e cinco tributários a drenagem para o ducto do lobo esquerdo. Os coletores conspícuos deste ducto mostram-se, em número de um $(53,3 \%$ -
$50,0 \%-33,3 \%)$ ou dois $(26,7 \%-20,0 \%$ - 3,3\%), nos equiinos, asininos e muares e, de três $(3,3 \%-3,3 \%)$, somente nos dois primeiros.

No que tange ao ducto acessório (de Santorini) ressaltamos, de início, que exclusivamente no Equus caballus ele deixa de ser caracterizado, em rara oportunidade $(3,3 \%)$; em ocasiāo similar $(3,3 \%)$, mostra a extremidade central livre, acontecimento frontalmente diverso do usual, em eqüinos, asininos e muares, pois abrese, invariavelmente, no sistema do ducto principal (de Wirsung). De fato, o ducto acessório (de Santorini) busca sempre associar-se a um dos coletores componentes do aludido sistema e verificamos logo que percentagens ligadas a determinados aspectos pouco discordam entre dois dos conjuntos de animais divergindo, contudo, do terceiro deles. Tal é a condição das peças nas quais o focado ducto desemboca no próprio ducto principal (de Wirsung) (asininos - 53,3\%; muares - 56,7\%; eqüinos - 76,6\%), no ducto do lobo esquerdo (asininos - 23,3\%; muares - 20,0\%; eqüinos - 10,0\%) ou no ducto do lobo direito (eqüinos $-3,3 \%$; muares $-6,7 \%$; asininos - 23,3\%). Não oferecem oportunidade de confronto as dissecçōes que pertencem apenas aos eqüinos e apresentam o ducto acessório (de Santorini) relacionado com o ângulo constituido pelo ducto principal (de Wirsung) e ducto do lobo esquerdo (eqüinos - 3,3\%); outra não é a situação de alguns dos pâncreas relativos aos muares, pois somente neles encontramos o ducto acessório (de Santorini) ligado a contingente conspícuo do próprio ducto principal (de Wirsung) $(6,7 \%)$, do ducto do lobo direito $(6,7 \%)$ ou do ducto do lobo esquerdo $(3,3 \%)$. Ao percorrer a correspondente zona parenquimatosa, o ducto acessório (de Santorini) pode mostrar-se livre de tributários (eqüinos - 26,7\%) ou recebe-los em número variável. A maior parte das modalidades anotadas surge exclusivamente em 
PRADA, I. L. Je S. et al. - Contribuição ao estudo do sistema excretor do pâncreas em muares (Equus caballus $\mathrm{x}$ Equus asinus). Rev. Fac. Med. vet. Zootec. Univ. S. Paulo, 1.1: 271-93, 1974.

dois dos conjuntos de animais e os respectivos valores pouco ou nada divergem entre si; assim, registramos, para eqüinos e asininos, pâncreas com um coletor $(26,7 \%-20,0 \%)$, relativamente a asininos e muares, órgãos portadores de cinco aferentes $(13,3 \%-13,3 \%)$ e, no que tange a eqüinos e muares, peças com seis $(3,3 \%-6,7 \%)$ e oito contingentes $(3,3 \%-3,3 \%)$. No atinente aos tipos encontrados simultaneamente em eqüinos, asininos e muares, o de três coletores exibe percentagens apartadas $(6,7 \%-36,7 \%$ $-26,7 \%)$, enquanto no de dois $(23,3 \%$ $20,0 \%-6,7 \%)$ e quatro $(6,7 \%-10,0 \%$ - $36,7 \%$ ) tributários, elas assim se destacam em apenas um dos grupos. Ainda, assinalamos a ocorrência de glândulas com sete afluentes $(6,7 \%)$, para os muares, disposição não acusada em Equus caballus e Equus asinus.

Atentamos agora para as vias anastomóticas descritas, que interligam diversos coletores pancreáticos de eqüinos, asininos e muares; nos três grupos, elas unem os ductos dos lobos direito e esquerdo através da ponte sendo, entretanto, muito mais frequentes no Equus caballus $(56,7 \%$ $10,0 \%-13,3 \%)$. Registramos, ainda, a ocorrência de conexão entre as secções distais dos ductos dos lobos direito e esquerdo $(6,7 \%)$ e diferentes tractos do primeiro $(3,3 \%)$, aspectos característicos dos eqüinos, como o são, nos asininos, os referentes à comunicação do ducto principal (de Wirsung) com o ducto do lobo esquerdo $(3,3 \%)$ e o ducto acessório (de Santorini) - $(3,3 \%)$.

Por fim, julgamos oportuno lembrar, após as considerações feitas, que a descrição única oferecida por BOURDELLE e BRESSOU 1 (1937) para o pâncreas dos eqüídeos (eqüinos, asininos e muares), torna-se viável apenas quando focalizados os aspectos morfológicos mais genéricos do sistema excretor do órgāo, pois dela esca- pam as disposições particulares a cada um, demonstradas pela pesquisa sistemática.

\section{O N C L U S O E S}

Com base nos resultados obtidos com a dissecção do pâncreas de 30 muares adultos (15 machos e 15 fêmeas), estabelecemos as seguintes conclusões:

1. O sistema excretor do pâncreas dos muares tem, como vias mais importantes, o ducto principal (de Wirsung), o ducto do lobo direito, o ducto do lobo esquerdo e o ducto acessório (de Santorini).

2. O ducto principal (de Wirsung) constitui-se pela união do ducto do lobo direito e ducto do lobo esquerdo e recebe, ao percorrer o corpo do pâncreas, numerosos afluentes, isto é: três $(23,3 \%)$, quatro $(23,3 \%)$, dois $(20,0 \%)$, cinco $(20,0 \%)$, um $(6,7 \%)$, seis $(3,3 \%)$ e sete $(3,3 \%)$. Em $20,0 \%$ das preparaçōes, um dos citados afluentes destaca-se pela amplitude de calibre e da correspondente região de escoamento.

3. O ducto do lobo direito representa - mais importante coletor da regiāo, de onde acolhe muitos tributários, ou seja: onze $(20,0 \%), \operatorname{dez}(16,7 \%)$, nove $(13,3 \%)$, oito $(10,0 \%)$, doze $(10,0 \%)$, seis $(6,7 \%)$, sete $(6,7 \%)$, cinco $(3,3 \%)$, treze $(3,3 \%)$, catorze $(3,3 \%)$, quinze $(3,3 \%)$ e dezesseis $(3,3 \%)$. Em 50,0\% das peças, um $(46,7 \%)$ ou dois $(3,3 \%)$ destes tributários surgem conspícuos.

4. O ducto do lobo direito pode transitar pela porção caudal do lobo esquerdo $(13,3 \%)$, daí recolhendo diversos coletores, a saber: seis $(6,7 \%)$, quatro $(3,3 \%)$ e oito $(3,3 \%)$. Em 3 dos casos apontados $(10,0 \%)$, um dos referidos coletores exibe grande calibre e drena mais amplos territórios glandulares. 
PRADA, I. L. de S. et al. - Contribuição ao estudo do sistema excretor do pâncreas em muares (Equus caballus $\mathbf{x}$ Equus asinus). Rev. Fac. Med. vet. Zootec. Univ. S. Paulo, 11: 271-93, 1974.

5. O ducto do lobo esquerdo caminha ao longo da correspondente região pancreática e a ele vão ter inúmeros afluentes, mais exatamente: treze $(20,0 \%)$, doze $(13,3 \%)$, dezesseis $(13,3 \%)$, dezenove $(10,0 \%)$, onze $(6,7 \%)$, catorze $(6,7 \%)$, quinze $(6,7 \%)$, dezessete $(6,7 \%)$, cinco $(3,3 \%)$, sete $(3,3 \%)$, nove $(3,3 \%)$, dezoito $(3,3 \%)$ e vinte e quatro $(3,3 \%)$. Em $36,7 \%$ dos casos, um $(33,3 \%)$ e dois $(3,3 \%)$ dos mencionados afluentes mostram-se conspícuos.

6. O ducto acessório (de Santorini) percorre massa glandular restrita, incompletamente separada da face ventral do corpo do pâncreas por plano de tecido conjuntivo. Por intermédio de sua extremidade central, abre-se diretamente no ducto principal (de Wirsung) -. $(56,7 \%)$, no ducto do lobo esquerdo $(20,0 \%)$, no ducto do lobo direito $(6,7 \%)$ ou em tributário conspícuo do primeiro ducto $(6,7 \%)$, do terceiro $(6,7 \%)$ e do segundo $(6,7 \%)$.

7. O ducto acessório (de Santorini), por sua extremidade periférica, avizinhase do duodeno e, independentemente da presença de papila, alcança-o muitas vezes $(80,0 \%)$, embora em algumas delas $(30,0 \%)$ nem o ar nem a massa injetados no sistema excretor do pâncreas consigam atingir, por intermédio dela, a luz intestinal.

8. O ducto acessório (de Santorini) recebe, durante seu trajeto, diversas contribuições ,isto é: quatro $(36,7 \%)$, três $(26,7 \%)$, cinco $(13,3 \%)$, dois $(6,7 \%)$, seis $(6,7 \%)$, sete $(6,7 \%)$ e oito $(3,3 \%)$.

9. Vias anastomóticas de calibres diversos interligam $(13,3 \%)$, por intermédio da ponte, os ductos dos lobos direito e esquerdo.

RFMV-A/26

Prada, I. L. de S. et al. - Contribution to th estudy of the pancreatic system in mules (Equus caballus $x$ Equus asinus). Rev. Fac. Med. vet. Zootec. Univ. S. Paulo, 11:271-93, 1974.

SUMMARY: The results of this investigation showed that the Wirsung duct proceeds from the union of the collectors of the right and left lobes and receives, as well as their roots, varied number of affluents. The collector of the right lobe also strains $(13.3 \%)$ the posterior portion of the left lobe.

The Santorini duct opens, by its central extremity, directly in the Wirsung duct $(56.7 \%)$, in the duct of the left lobe $(20.0 \%)$, in the duct of the right lobe $(6.7 \%)$ or in main affluents of the Wirsung duct $(6.7 \%)$, of the duct of the right lobe $(6.7 \%)$ and of the duct of the left lobe $(3.3 \%)$.

The $A A$. indicated also the presence of the anastomosis communicating some times $(13.3 \%)$ the collectors of the right and left lobes.

Unitrrms: Mules*; Pancreas*; Pancreatic ducts*; Anatomy*; Digestive system.

\section{REFERENCTAS BIBLIOGRAFICAS}

1. BOURDELLE, E. \& BRESSOU, C. Anatomie régionale des animaux domestiques. 2.: ed. Paris, J. B. Balllière, 1937. v. 1 , p. 793-94.
2. BRADLEY, O. C. - The topographical anatomy of the thorax and abdomen of the horse. Edinburg, W. Green \& Son, 1922. p. 117-18. 
PRADA, I. L. de S. et al. - Contribuiçāo ao estudo do sistema excretor do pâncreas em muares (Equus caballus $\mathrm{x}$ Equus asinus). Rev. Fac. Med. vet. Zootec. Univ. S. Paulo, 11: 271-93, 1974.

3. BRUNI, A. C. \& ZIMMERL, U. - Anatomia degli animali domestici. Milano, Francesco Vallardi, 1947. v. 2 , p. $86-8$.

4. CARADONNA, G. B. - Apparecchio gastropolmonare. In: ZIMMERL, U. Trattato di anatomia veterinaria. Milano, Francesco Vallardi, 1930. v. 2 , p. $573-82$.

5. ElleNBERGER, W. \& BAUM, H. Handbuch der vergleichenden anatomie der haustiere. 17.a ed. Berlin, Julius Springer, 1932. p. 259-60.

6. FAVILLI, N. - Nozioni comparate di anatomia e fisiologia degli animali rurali. Torino, Unione Tipografico — Editrice Torinese, 1931. p. 319-23.

7. Gonzalez y GaRcia, J. \& AllvaREZ, R. G. - Anatomia comparada de los animales domesticos. $7 .^{\mathrm{a}}$ ed. Madrid, Gráfica Canales, 1961. p. 492-94 .

8. KATO, K. - Anatomia comparada dos animais domésticos. Toquio, Yokendo, 1961 . v. 1, p. 104-5.

9. LEPOUTRE, L. - Notes du cours d'anatomie comparée des animaux domestiques. Gembloux, J. Duculot, 1921. p. $147-48$.

10. LESBRE, F. X. - Précis d'anatomie comparée des animaux domestiques. Paris, J. B. Baillière, 1922 . v. 1, p. 665-68.

11. LORDY, C. - In: LORDY, C. et al. Embriologia humana e comparada (Ontogênese e teratogênese). São Paulo, Melhoramentos, 1940. p. 403-9.

12. MONGIARDINO, T. - Trattato di anatomia topografica dei mamiferi domestici. Torino, Luigi Delgrosso, 1903. p. 187-88.

13. MONTANE, L. \& BOURDELLE, E. Anatomie régionale des animaux domestiques. Paris, J. B. Baillière, 1913. v. 1, p. $890-91$.

14. PAIVA, O. M. de et al. - Contribuição ao estudo do sistema excretor do pâncreas em búfalos (Bubalus bubalis - Linnaeus, 1758). Rev. Fac. Med. vet. Zootec. Univ. S. Paulo, 9:43-54, 1972 .
15. PAIVA, O. M. de et al. - Contribuição ao estudo do sistema excretor do pâncreas em eqüinos. Rev. Fac. Med. vet. Zootec. Univ. S. Paulo, $10: 103-22,1973$.

16. Peduti neto, J. - Contribuição ao estudo das vias excretoras do pâncreas em Equus asinus. Sistematização do ducto principal (de Wirsung) e do ducto acessório (de Santorini). Sāo Paulo, 1972. [Tese Faculdade de Medicina Veterinária e Zootecnia da Universidade de São Paulo]

17. PRADA, I. L. de S. - Contribuiçāo ao estudo do sistema excretor do pâncreas em bovinos (Bos taurus) de origem européia. Rev. bras. Biol., 30:355-66, 1970.

18. PRADA, I. L. de $\mathrm{S}$. et al. - Sobre as comunicacões do sistema excretor do pâncreas com o duodeno, em equideos. Rev. Fac. Med. vet. (S. Paulo), 8(2):411-16, 1970.

19. PRADA, I. L. de $\mathrm{S}$. et al. - Contribuição ao estudo do sistema excretor do pâncreas em bovinos azebuados. Arch. Inst. biol. (S. Pau-

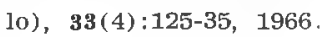

20. SCHMALTZ, R. - Anatomie des Pferdes. Berlin, Richard Schoeltz, 1928. p. 466-67.

21. SCHUMMER, A. \& NICKEL, R. - Eingeweide. In: NICKEL, R. et al. Lehrbuch der anatomie der haustiere. Berlin, Paul Parey, 1960. v. 2, p. 118-20.

22. SISSON, S. \& GROSSMANN, J. D. Anatomia de los animales domesticos. Barcelona, Salvat Editores, 1965. p. $415-16$.

23. ZANOLLI, C. - Manual de anatomia veterinaria. La Plata, Félix F. Santi, 1910 . v. 1, p. $347-48$.

24. ZIMMERL, U. - Anatomia topográfica veterinária. Milano, Francesco Vallardi, 1949. p. 318-19.

Recebido para publicação em 28-8-74

Aprovado para publicação em 29-8-74 